\title{
Guidelines for a better management of all forms of topical ozonetherapy in diabetic foot ulcer [abstract]
}

\author{
Michele Angelo Farina1, Claudia Cardoso², Roberto Dall'Aglio³ \\ ${ }^{1}$ M.D, Vascular Surgeon. Caserta. Italy. ${ }^{2}$ Consultant, SSICA, Parma, Italy. ${ }^{3}$ Università di Milano, Dip. Farmacologia. \\ Milan. Italy
}

\section{ABSTRACT}

\section{О OPEN ACCESS}

\section{Citation}

Farina M.A, Cardoso C, Dall'Aglio R. Guidelines for a better management of all forms of topical ozonetherapy in diabetic foot ulcer [abstract]. Proceedings of The World Conference on Ozone Therapy in Medicine, Dentistry and Veterinary. Ancona (Italy). September 22nd - 23rd - 24th , 2017. J Ozone Ther. 2019;3(4):14. doi: 10.7203/jo3t.3.4.2019.15419

\section{Academic Editor}

Jose Baeza-Noci,

School of Medicine, Valencia

University, SPAIN

\section{Editor}

World Federation of Ozone Therapy, Bolgna, ITALY

\section{Received}

June 17, 2019

\section{Accepted}

December 08, 2019

Published

December 30, 2019

\section{Intellectual Property}

Michele Angelo Farina.

This is an open access article distributed under the terms of the Creative Commons Attribution License (CC BY 4.0), which permits unrestricted use, distribution, and reproduction in any medium, provided the original author and source are credited.

\section{Author Information}

Email: angiofar@libero.it
Foot ulcers result in substantial morbidity, reduced quality of life, and increased mortality in patients with diabetes.

The risk of these ulcers becoming chronically infected is well above $60 \%$. About $50 \%$ of patients undergoing non-traumatic lower limb amputations have diabetes. These patients have a high mortality following amputation, ranging from $39 \%$ to $80 \%$ at 5 years.

Some developments have been made towards the treatment of this complication with surgical intervention, topical antiseptics, and systemic antibiotic therapy; however, outcomes continue to remain poor and lead to limb amputation in $15 \%$ to $20 \%$ of patients within 5 years of the time of initial infection.

As an additional alternative, topical ozone therapy could be done by following the main steps: hydrate and start the debridement of the lesion with ozonized water to enable the penetration of the ozone oxygen mixture.

Afterwards, start the bagging with the gas mixture, beginning with high concentrations, more frequently in the initial phases, and reduce as the process proceeds.

The water or oil prepared with ozone can be useful to control infection inside the wound and accelerate the metabolism in surrounding soft tissues. Therefore, facilitate healing.

The patient can thus underwent conservative surgery for removing the necrotic area or osteomielitys.

No side effects have been noticed during treatment. Neither allergies nor skin dermatitis were found and frequently the utilization of this therapy shortened the healing period. 